\title{
Evaluation of educational technology on pressure injury based on assistance quality indicators
}

\author{
Avaliação de tecnologia educativa sobre lesão por pressão baseada em indicadores de \\ qualidade assistenciais
}

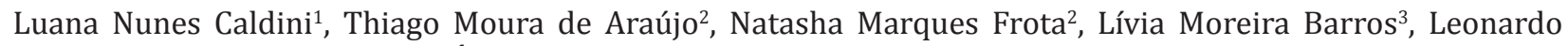
Alexandrino da Silva ${ }^{4}$, Joselany Áfio Caetano ${ }^{4}$

Objective: to evaluate the contribution of educational technology on pressure injury regarding assistance quality indicators. Methods: a quasi-experimental study, with the design before and after the educational intervention, related to an online course on pressure injury. Data collection was done in three phases: the gathering of pressure injury indicators; implementation of the educational intervention; and post-intervention evaluation of the patients. Results: 47 patients were evaluated in each phase. The risk assessment and the description of the skin in the admission presented higher figures after the educational intervention. Description of preventive measures was higher in the educational post-intervention group, which presented a high-level index in the pre-intervention group (80.9\%). The number of patients with pressure injury decreased from $53.2 \%$ to $42.6 \%$ $(p=0.500)$. Conclusion: the impact of the communication and information technology was observed, especially on the decrease of occurrence of injuries.

Descriptors: Wounds and Injuries; Pressure Ulcer; Education, Distance; Intensive Care Units; Inservice Training; Nursing.

Objetivo: avaliar a contribuição de tecnologia educativa sobre lesão por pressão em indicadores de qualidade assistenciais. Métodos: estudo quase experimental, com delineamento antes e depois de intervenção educativa, relacionada a curso on-line sobre lesão por pressão. Coleta de dados composta por três etapas: recolhimento de indicadores sobre lesão por pressão; aplicação da intervenção educativa; e avaliação dos pacientes pósintervenção. Resultados: foram avaliados 47 pacientes em cada etapa. A avaliação de risco e descrição da pele na admissão apresentou valores superiores após intervenção educativa. Descrição de medidas preventivas foi superior no grupo pós-intervenção educativa, o qual apresentava elevado índice no grupo pré-intervenção (80,9\%). 0 número de pacientes com lesão por pressão diminuiu de $53,2 \%$ para $42,6 \%$ (p=0,500). Conclusão: 0 impacto da tecnologia de informação e comunicação foi observado, principalmente na diminuição da incidência de lesões.

Descritores: Ferimentos e Lesões; Úlcera por Pressão; Educação a Distância; Unidade de Terapia Intensiva; Capacitação em Serviço; Enfermagem.

\footnotetext{
${ }^{1}$ Faculdade Rodolfo Teófilo. Fortaleza, CE, Brazil.

${ }^{2}$ Universidade da Integração Internacional da Lusofonia Afro-Brasileira. Redenção, CE, Brazil.

${ }^{3}$ Universidade Estadual Vale do Acaraú. Sobral, CE, Brazil.

${ }^{4}$ Universidade Federal do Ceará. Fortaleza, CE, Brazil.

Corresponding author: Joselany Áfio Caetano

Rua Alexandre Baraúna, 1115. Rodolfo Teófilo. CEP: 60.416-000. Fortaleza, CE, Brazil. E-mail: joselany@ufc.br
} 


\section{Introduction}

The proposal for training programs is usually developed within the health institution, managed by the continuing education program, or by specialized companies contracted for such purpose. Currently, training and qualification programs are key in the analysis of assistance indicators, in promoting the patient's safety, on the occurrence of adverse events and their severity. In nursing, these indicators are essential when monitoring the quality of the assistance and to the evaluation of the needs for a redirection of the professionals. Among these indicators, there are those related to pressure injuries, found mainly in critical care units ${ }^{(1)}$.

The incidence and prevalence rates of pressure injury vary in different sceneries of care and the highest proportions are found in patients under intensive care and the elderly with neurologic and mobility deficit. In the United States, it is observed a prevalence of pressure injuries from $8.8 \%$ to $9.3 \%$, in critical patients $^{(2)}$ On the Brazilian context, it is observed a prevalence of $18.8 \%$ of pressure injuries, in the institutionalized elderly; and from $17.7 \%$ to $35.2 \%$, in subjects under intensive care units ${ }^{(3)}$.

The incidence of pressure injuries has also become an important indicator of the quality of nursing care, making possible to analyze cases regarding its distribution, patients' vulnerability and places they are more frequent. This indicator is used to guide preventive measures for the injury, supports the planning, the management and the evaluation of the nursing actions, besides guiding the nursing team through educational actions ${ }^{(3)}$.

Researches show the importance of reducing the incidence of pressure injuries by prevention and risk factors identification, what can be done through permanent education of the multi-professional team, with practice based on evidence, when it is established the relationship between the knowledge and the clinical experiences ${ }^{(4-5)}$.
Undeniably, the technology emerges as a valuable tool to the solution of the pressure injury problematics, because besides the technologies related to products and processes for the prevention and treatment of pressure injuries, it has increased the possibilities of developing information and communication technologies to answer to the qualification needs of health professionals ${ }^{(6)}$.

Having said that, because it is something new in the assistance practice, there are still many limitations by health professionals regarding the use of communication and information technologies. In this context, nurses present gaps related to the use of these technologies, to the knowledge of computing and to the lack of motivation to use these resources, as well as the shortage of studies that demonstrate evidence of the effectiveness of this use in the qualification of these professionals ${ }^{(7)}$.

The evaluation of the training and qualification results has as the main role to seek for improvement in actions, supporting the decisions and reorienting initiatives, what generates changes on the way planning and resources are acquired, becoming a criticism mechanism ${ }^{(8)}$. The evaluation of educational programs aims to identify whether the proposed goals were reached, what implies practical results measurements and impact on the work. In order to find the influence of these programs on the practice of the trainer, one of the most used strategies has been to compare levels of knowledge and the professional performances before and after being submitted to the educational intervention $^{(9)}$.

When considering the importance of this theme, the nurse's actions when taking care of the pressure injury patient and the incremental use of educational technologies, it was defined as the objective to evaluate the contribution of the educational technology on the pressure injury regarding the quality assistance indicators. 


\section{Methods}

A quasi-experimental study, with design before and after the use of the communication and information technology (educational intervention) on pressure injury. The sample was composed of patients hospitalized in the intensive care unit, of a large university hospital, in the city of Fortaleza, Ceará state, Brazil. Eligibility criteria was used only for the composition of the patients sample: age - over 18 years, and the risk of pressure injury was obtained from an worldwide accepted scale ${ }^{(10)}$. Subjects were excluded when their time of stay was below 48 hours at the unit, due to the short period of assessment of selected indicators.

During the study period, there was the admission of 69 patients before intervention and 73 patients after the intervention. From these, after applying the criteria for inclusion and exclusion, resulted in a sample of 47 patients before and after the intervention. Regarding the nurses, those who accepted to participate in the study were included, resulting in a total number of nine professionals.

The period of data collect was from June to December 2015, divided in three phases. In the first phase was done the collection of the quality assistance indicators related to the prevention and treatment for pressure injury on the patients' medical reports and the evaluation of the patients before (first group) the use of the educational intervention and, in the second phase, the communication and information technology was employed with the nurses. In the third phase, there was the collection of the quality assistance indicators, related to the prevention and treatment for pressure injury, and the evaluation of the patients after (second group) the educational intervention.

In the first phase, in order to collect indicators before and after intervention, an application form was elaborated to data collect of relevant information related to the patients assisted in the intensive care unit, such as social data (age, gender); and cares related to the prevention and treatment for pressure injury, such as the injury description, area of injury and nurse care. In the second phase, the educational intervention was applied. The communication and information technology used in this study was developed by the Nursing School of the University of São Paulo, which was submitted to the validation process by specialists ${ }^{(11)}$. The communication and information technology is self-taught and it has a workload of 20 hours and encompasses the physiopathology aspects of the pressure injury, as well as prevention and treatment, currently, it is inserted in the platform Moodle of the referred institution, under the title, "Course Ulcer by Pressure Online". Initially, it was established a time frame of 30 days for the beginning and conclusion of the course, although it was extended for an additional 60-day period. It is emphasized that the evaluation of this communication and information technology was performed in this study by the comparison of the indicators before and after the implementation of the course.

The collected data were organized and tabulated with Microsoft Office Excel $^{\circledR} 2010$ and analyzed with the Software of Statistics Analysis SAS for Win$\operatorname{dows}^{\circledR}$ (version 9.3) for variable crossing and to perform the statistic tests Chi-squared, Student's t-test, Fisher's Exact Test, and U by Wilcoxon-Mann-Whitney Test. It was also generated the calculation of mean, median, standard deviation and confidence interval. It was considered the significance level of $5 \%(p<0.050)$. The presentation of the data was carried out on tables with a direct description of the information.

The study complied with the formal requirements contained in the national and international regulatory standards for research involving human beings, approved by the Research Ethics Committee, with CAEE: 42410915,0,0000,5576.

\section{Results}

Ninety-four patients were evaluated, 47 of them before and 47 after the intervention. In the first phase of the study, those 47 evaluated patients make up for 
$68.1 \%$ of the hospitalized individuals, who were on total of 69 patients. In the second phase, 73 patients were admitted, whereas $64.4 \%$ were investigated.

Regarding the patients, 56 (59.6\%) were female. Regarding age groups, it was found that the most prevalent group was $\geq 61$ years (51.1\%), with an average of age 56.45 (DP \pm 19.14 ).

Concerning the reasons for the admission into the intensive care unit, three systems stood out as the causes for admission before the intervention: 14 (29.8\%) due to cardiovascular; 11 (23.4\%) hepatic; and $11(23.4 \%)$ respiratory. After the intervention, three causes for admission stood out: 15 (31.9\%) due to cardiovascular; 12 (25.5\%) sepsis; and 12 (25.5\%) respiratory. The number of deaths was 17 (36.2\%) among patients before the educational intervention, and $20(28.3 \%)$ after, observing in this relation $\mathrm{p}=0.164$. Concerning the variables: age, gender, cause of admission, origin, death, and clinical history, there were no significant statistical differences among the patients in the two phases of the data collect.

In Table 1, there is a description of variables related to the pressure injury and some quality assistance indicators for these types of injuries: risk assessment, skin evaluation in the admission and description of preventive measures. The risk assessment for pressure injury in the admission was superior in the second group, with 34 (72.3\%) patients assessed. The skin description was not performed in 27 (57.4\%) of the evaluated patients, on the first group, whereas the second group had this description slightly above half of the subjects, 24 (51.0\%).

The description of preventive measures, regarding the patients evaluated before and after the intervention, presented a high percentage, above $90.0 \%$, in the second group. As preventive measures on the patients' records, stood out: use of the Braden risk assessment scale, use of pyramidal and air/water mattresses, usage of skin moisturizer products, protective dressing on risk areas in order to prevent pressure injuries, skin hygiene and change of decubitus. The initial risk assessment was done with an institutional form of nursing assistance systematization.

It was observed that the indicators of risk assessment for pressure injuries in the admission, of skin description and of preventive measures showed a higher percentage after the educational intervention, but statistical difference was not found ( $p>0.050$ ).

Table 1 - Distribution of risk assessment in the admission, of skin description and of preventive measures in patients evaluated before and after the educational intervention $(n=47)$

\begin{tabular}{|c|c|c|c|c|c|}
\hline \multirow{2}{*}{ Variables } & \multicolumn{2}{|c|}{ Before } & \multicolumn{2}{|c|}{ After } & \multirow{2}{*}{$\mathbf{p}^{* *}$} \\
\hline & $n(\%)$ & $\mathbf{C I}^{*}$ & $n(\%)$ & $\mathbf{C I}^{*}$ & \\
\hline \multicolumn{6}{|c|}{ Risk assessment in the admission } \\
\hline Yes & $26(55.3)$ & $40.12-69.83$ & $34(72.3)$ & $57.36-84.38$ & \multirow{2}{*}{0.839} \\
\hline No & $21(44.7)$ & $30.17-59.88$ & 13 (27.7) & $15.62-42.64$ & \\
\hline \multicolumn{6}{|c|}{ Skin description in the admission } \\
\hline Yes & $20(42.6)$ & $28.26-57.82$ & $24(51.0)$ & $36.06-65.92$ & \multirow{2}{*}{0.865} \\
\hline No & $27(57.4)$ & $42.18-71.74$ & $23(49.0)$ & $34.08-63.94$ & \\
\hline \multicolumn{6}{|c|}{$\begin{array}{l}\text { Description of the pre- } \\
\text { ventive measures }\end{array}$} \\
\hline Yes & $38(80.9)$ & $66.74-90.85$ & $43(91.5)$ & $79.62-97.63$ & \multirow{2}{*}{0.723} \\
\hline No & $9(19.1)$ & $9.15-33.26$ & $4(8.5)$ & $2.37-20.38$ & \\
\hline
\end{tabular}

When counting the injuries, it was taken into consideration the total number of pressure injuries in the admission and after the hospitalization. The highest occurrence happened in the first group, which 25 (53.2\%) patients presented injuries. However, it is necessary to highlight that 19 (40.4\%) patients presented pressure injury in the admission, whereas the second group presented 14 (29.8\%). The occurrence of pressure injury in the admission before and after the intervention showed a significant statistical difference $(\mathrm{p}=0.046)$. The description of interventions with patients was higher in the second group and it did not show statistical difference when compared to the first group ( $\mathrm{p}=0.399)$ (Table 2). 
Table 2 - Distribution of pressure injury for the patients before and after the educational intervention $(\mathrm{n}=47)$

\begin{tabular}{llllll}
\hline \multirow{2}{*}{ Variables } & \multicolumn{2}{c}{ Before } & \multicolumn{2}{c}{ After } \\
\cline { 2 - 5 } & $\mathbf{n}(\%)$ & $\mathbf{C I}^{* *}$ & $\mathbf{n}(\%)$ & $\mathrm{CI}^{*}$ & \\
\hline
\end{tabular}

Patients with pressure injury

$\begin{array}{ll}\text { Yes } & 25(53.2) 38.08-67.8920(42.6) 28.26-57.82 \\ \text { No } & 22(46.8) 32.11-61.9227(57.4) 42.18-71.74\end{array}$

Pressure injury in the admission

Yes

19 (40.4) 26.37-55.73 14 (29.8) 17.34-44.89 28 (59.6) 44.27-73.63 33 (70.2) 55.11-82.66

No

Description of interventions

Yes

35 (74.5) 59.65-86.96 42 (89.4) 76.90-96.45

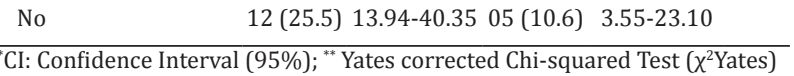

The data related to the number of patients and of injuries, before and after the educational intervention, was identified by a descriptive way: 15 (31.9\% and $\mathrm{CI}=19.09-47.12$ ) patients developed pressure injury after the admission in the pre-intervention group; and 9 (19.1\% and $\mathrm{CI}=9.15-33.26)$ in the post-intervention group, however, there was no significant statistical difference between groups, with value of $\mathrm{p}=0.236$.

The patients before the educational intervention presented a frequency of 55 injuries, of those, 26 (47.8\%) developed after admission. The subjects evaluated after the educational intervention presented a frequency of 29 injuries, of those, 12 (41.4\%) develo- ped after admission. The difference in the number of injuries before and after the educational intervention was 26 injuries and the difference of the injuries developed only after the admission into the intensive care unit was 14 cases. Some patients presented more than one injury.

The patients with skin injury before and after the educational intervention presented a variation in the number of injuries, however, for the calculation of the prevalence of the pressure injury in the intensive care unit, it was taken into consideration both, the total number of patients with injury, as well the number of patients admitted in the period, which was 69 , in the first group; and 73, in the second. Therefore, it was identified the prevalence of pressure injuries of $36.2 \%$ and $27.4 \%$, in the first and second groups respectively. The occurrence of pressure injury was $31.9 \%$ and $19.1 \%$, in the period before and after the educational intervention, respectively. It was found a difference of $12.8 \%$ of new pressure injury cases between the groups.

The mean of admission, calculated in days was higher in the pre-intervention group, consequently, the other items presented higher figures when related to the post-intervention group. The difference in days of hospitalization between groups pre and post-admission was 4.47 days. The mean of hospitalization days in the intensive care unit and the occurrence of pressure injuries in the admission presented significant statistical association only in the pre-educational intervention group ( $\mathrm{p}=0.043$ ) (Table 3 ).

Table 3 - Distribution of the mean of days of hospitalization, risk assessment and description of pressure injury on the patients that presented injury before and after the educational intervention $(n=47)$

\begin{tabular}{|c|c|c|c|c|c|c|c|c|c|}
\hline \multirow[b]{2}{*}{ Variables } & \multicolumn{4}{|c|}{ Before } & \multicolumn{4}{|c|}{ After } & \multirow[t]{2}{*}{$\mathbf{p}^{*}$} \\
\hline & Mean & $\begin{array}{l}\text { Standard } \\
\text { Deviation }\end{array}$ & Minimum & Maximum & Mean & $\begin{array}{l}\text { Standard } \\
\text { Deviation }\end{array}$ & Minimum & Maximum & \\
\hline Hospitalization (days) & 17.92 & $( \pm 20.56)$ & 3 & 102 & 13.45 & $( \pm 8.90)$ & 4 & 31 & 0.903 \\
\hline Risk Assessment (days) & 8.72 & $( \pm 16.65)$ & - & 86 & 4.40 & $( \pm 4.33)$ & - & 20 & 0.211 \\
\hline Description of injury (days) & 7.84 & $( \pm 16.65)$ & - & 84 & 5.65 & $( \pm 5.01)$ & - & 17 & 0.596 \\
\hline
\end{tabular}


Compared to the mean hospitalization days, there was a higher proportion of risk assessment in the first group (48.7\%) in relation to the second group $(32.7 \%)$. Proportionally, the first group had a discreet higher figure (43.7\%) in relation to the second group, regarding the item description of the injury in days $(p=0.596)$. Despite that, it is important to emphasize that the daily description of the pressure injuries by the participant nurses reached a percentage below $50.0 \%$ in both groups. Among the patients with pressure injuries there was no significant difference in days of hospitalization, risk assessment and description of the injury ( $p>0.005)$. Therefore, it was observed that the first group showed a higher mean of hospitalization days, contributing to more days of risk assessment in the first group (Table 3).

\section{Discussion}

This study presents limitations deriving from the methodological layout implemented, such as cross-sectional and punctual evaluation of the investigated variables, what may become an obstacle to the generalization of the results to other realities.

The evaluation of patients before and after the educational intervention showed similarities regarding demographic and clinical characteristics of the 47 patients evaluated in each group. Although the intervention had been performed directly with the nurses, the clinical condition of the patients plays a primary role in the evaluation of health indicators related to the prevention and treatment of pressure injuries, with this aspect discussed within the course used in this research.

After the educational intervention, it was observed an increase in the risk assessment, skin description, and preventive measures in the studied intensive care unit. In a study carried out among 468 patients, the prevalence of pressure injuries decreased from $6.6 \%$ to $2.5 \%$, after educational intervention ${ }^{(9)}$. In a randomized clinical trial performed in 29 European asylum like institutions that analyzed educational interventions and monthly on-site orientations on pressure injury, in the items: urinary incontinence, weight loss and decreasing daily activities of elderly people. These interventions improved significantly the quality of the service $(\mathrm{p}=0.020)$ and decreased the incidence of pressure injury $(\mathrm{p}=0.050)$ and of weight loss $(\mathrm{p}=0.050)$, in comparison with the European asylum like institutions that did not receive the educational intervention $^{(12)}$.

In accordance with the results of the previous research, another study that evaluated an educational campaign in a Brazilian school hospital, after 127 evaluations, it was identified an improvement in the repositioning $(\mathrm{p}=0.002)$, in the repositioning technique ( $\mathrm{p}=0.001)$, in the head-of-bed elevation below 45 degrees $(p<0.001)$ and in the elevation of the heels $(p<0.001)$. The campaign took place in two units and the adoption of the recommendations made by the National Pressure Ulcer Advisory Panel/European Pressure Ulcer Advisory Panel was higher in the sector that had more adherence to the educational action ${ }^{(13)}$.

Although the incidence of injuries is a clear and direct demonstration of the real situation of an institution regarding pressure injuries, other indicators that show the good quality of the nursing assistance must be considered. The description of interventions related to the cares with the patient in order to prevent injuries increased in the post-educational intervention group, although the nurses already use to describe interventions in more than $70.0 \%$ in the first group of patients evaluated. The description of the injury did not show improvement after the intervention. The concerning in describing the injury is reinforced by the majority of the protocols developed to the follow-up and prevention of the pressure injury, and it is one of the recommendations from the National Pressure Ulcer Advisory Panel and from the European Pressure Ulcer Advisory Panel, besides the relevance for monitoring patients and developed actions ${ }^{(14)}$.

Educational actions intended to the nutritional 
support, aiming an individual with injuries under treatment at outpatient level, were developed by American nurses who identified the lack of barriers on the adherence to the conduct applied in the actions and the low cost of this strategy. At the end of the intervention, the cost was less than eight dollars per patient ${ }^{(15)}$. These studies show the need to control the variables analyzed before and after in order to obtain fidelity in the results, as well as the feasibility of the proposed interventions.

The discussion about the use of scales for risk assessment to pressure injury does not nullify the responsibility of nurses to perform a rigorous evaluation to detect risk factors, including those that are not covered by the implemented instruments, such as age, gender, medicines and the performance of surgical procedures. The use of scales fosters the health of the patients because it better evaluates the possibility of developing pressure injury than a professional using individual knowledge separately. The scores that show risk help the professionals to perform more effective preventive cares, especially in subjects with lower scores or equal to 13 . Associated with these factors, the use of effective preventive measures decreases the predictive figure of the risk assessment scales for pressure injury ${ }^{(3,16)}$.

The use of online teaching fosters learning and stimulates nurses and nursing students to seek more information to meet the demands. A study shows a greater interest of the subjects about this theme, as well as an increase in the use of distance learning methodologies ${ }^{(17)}$.

The results point to the reality of an intensive care unit and the problematics of the pressure injuries influencing the routine and the prognosis of patients. The prevention actions must be considered as priorities in these sectors of critical care, due to the high risk to develop injuries. The educational interventions must follow the new educational models, mainly the online tools.

\section{Conclusion}

It was observed the positive impact of the adoption of the communication and information technology in an intensive care unit, mainly regarding the decreasing of the incidence and prevalence of pressure injury. The description and performance of preventive measures concerning the pressure injury, the risk assessment of patients in the admission and the initial description of the injury in stage 1 presented an increase after the educational intervention.

\section{Collaborations}

Caldini LN contributed to the design and project or analysis and data interpretation. Araújo TM and Barros LM contributed with writing of the article and relevant critical review of the intellectual content. Frota NM, Silva LA and Caetano JA helped with article writing, relevant critical review of the intellectual content and final approval of the version to be published.

\section{References}

1. Tobase L, Grareschi APDF, Frias MAE, Prado C, Peres HHC. Technological resources in nursing education. J Haelth Inform [Internet]. 2013 [cited 2018 May 28]; 5(3):77-81. Available from: http:// www.jhi-sbis.saude.ws/ojs-jhi/index.php/jhisbis/article/view/218

2. VanGilder C, Lachenbruch C, Algrim-Boyle $\mathrm{C}$, Meyer S. The international pressure ulcer prevalence $^{\mathrm{TM}}$ survey: 2006-2015A 10-year pressure injury prevalence and demographic trend analysis by care setting. J Wound Ostomy Continence Nurs. 2017; 44(1):20-8. doi: 10.1097/ WON.0000000000000292

3. Palhares VC, Palhares Neto AA. Prevalence and incidence of pressure ulcers in an intensive care unit. Rev Enferm UFPE on line [Internet]. 2014 [cited May 28, 2018]; 8(2):3647-53. Available from: 10.5205/reuol.4597-37683-1ED.0810supl201410 
4. Stuque AG, Sasaki VDM, Teles AAS, Santana ME, Rabeh SAN, Sonobe HM. Protocol for prevention of pressure ulcer. Rev Rene. 2017; 18(2):27282. doi: http://dx.doi.org/10.15253/21756783.2017000200018

5. Tayyib N, Coyer F, Lewis P. Saudi Arabian adult intensive care unit pressure ulcer incidence and risk factors: a prospective cohort study. Int Wound J. 2016; 13(5):912-9. doi: https://doi-org.ez11. periodicos.capes.gov.br/10.1111/iwj.12406

6. Queiroz FM, Aroldi JBC, Oliveira GDS, Peres HHC, Santos VLCG. Venous ulcer and compression therapy for nurses: development of online course. Acta Paul Enferm. 2012; 25(3):43540. doi: http://dx.doi.org/10.1590/S010321002012000300018

7. Gonen A, Sharon D, Lev-Ari L. Integrating information technology's competencies into academic nursing education - an action study. Cogent Educ. 2016; 4(1):1-9. doi: https://doi.org/10.1080/233 1186X.2016.1193109

8. Hinrichsen SL. Qualidade e segurança do paciente. Rio de Janeiro: Medbook; 2013.

9. Mallah Z, Nassar N, Badr LK. The effectiveness of a pressure ulcer intervention program on the prevalence of hospital acquired pressure ulcers: controlled before and after study. Appl Nurs Res. 2015; 28(2):106-13. doi: https://doi. org/10.1016/j.apnr.2014.07.001

10. Braden B, Bergstrom N. A conceptual schema for the study of the etiology of pressure sores. Rehabil Nurs. 2012; 25(3):105-10. doi: https:// doi.org/10.1002/j.2048-7940.2000.tb01879.x

11. Costa JB, Peres HHC, Rogenski NMB, Baptista CMC. An educational proposal to teach a pressure ulcer management course online to students and nursing professionals. Acta Paul Enferm. 2009; 22(5):607-11. doi: http://dx.doi.org/10.1590/ S0103-21002009000500002
12. Rantz MJ, Zwygart-Stauffacher M, Hicks L, Mehr D, Flesner M, Petroski GF, etal. Randomized multilevel intervention to improve outcomes of residents in nursing homes in need of improvement. J Am Med Dir Assoc. 2012; 13:60-8. doi: https://doi. org/10.1016/j.jamda.2011.06.012

13. Olkoski E, Assis GM. Application of measures for preventing pressure ulcers by the nursing team before and after an education campaign. Esc Anna Nery. 2016; 20(2):363-9. doi: http://dx.doi. org/10.5935/1414-8145.20160050

14. Smith IL, Nixon J, Brown S, Wilson L, Cloeman S. Pressure ulcer and wounds reporting in NHS hospitals in England part 1: audit monitoring systems. J Tissue Viabil. 2016; 25(1):3-15. doi: https://doi.org/10.1016/j.jtv.2015.11.001

15. Green LM, Ratcliffe D, Masters K, Story L. Educational intervention for nutrition education in patients attending an outpatient wound care clinic: a feasibility study. J Wound Ostomy Continence Nurs. 2016; 43(4):365-8. doi: 10.1097/WON.0000000000000238

16. Bredesen IM, Bjoro K, Gunningberg L, Hofoss D. Effect of e-learning program on risk assessment and pressure ulcer classification - a randomized study. Nurse Educ Today. 2016; 40:191-7. doi: https://doi.org/10.1016/j.nedt.2016.03.008

17. Frota NM, Barros LM, Araújo TM, Lopes MVO, Almeida PC, Caetano JA. Validation of educational hypermedia about peripheral venipuncture. Texto Contexto Enferm. 2015; 24(2):353-61. doi: http:// dx.doi.org/10.1590/0104-07072015003480013 